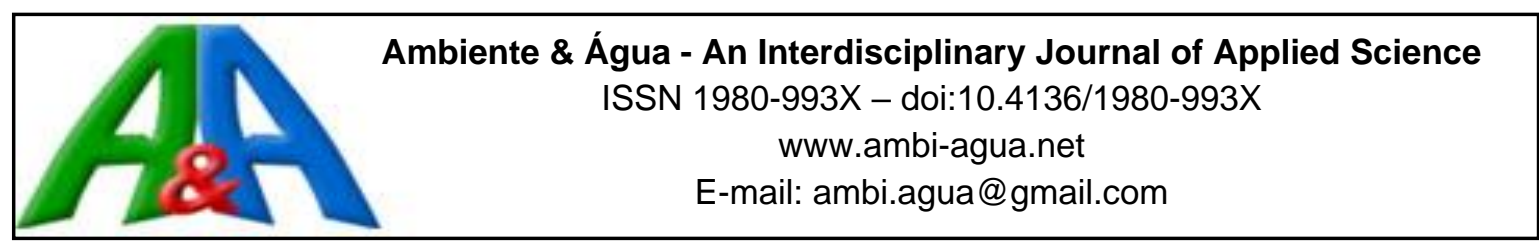

\title{
Resistência à penetração em Latossolo sob floresta ripária e submetido ao pisoteio animal
}

\author{
doi:10.4136/ambi-agua.1899
}

Received: 24 Aug. 2016; Accepted: 10 Nov. 2016

Larissa Chaves da Costa Vieira Paulo; Ana Aparecida da Silva Almeida ${ }^{*}$

${ }^{1}$ Universidade de Taubaté (UNITAU), Taubaté, SP, Brasil

Programa de Pós-Graduação em Ciências Ambientais

*Autor correspondente: e-mail: anaparecida.almeida@gmail.com,

1_biologa@yahoo.com.br

\section{RESUMO}

O pisoteio animal em condições de umidade inadequada são alguns fatores que provocam deformações plásticas e não recuperáveis do solo. No presente trabalho avaliaram-se as possíveis alterações em alguns atributos físico-químicos e na resistência mecânica à penetração, provocadas pelo pisoteio do gado por aproximadamente 20 anos sobre o Latossolo Vermelho Amarelo de um fragmento florestal, localizado em Tremembé (SP). Foram coletadas amostras com estrutura preservada nas camadas de $0-20 \mathrm{~cm}$ e $20-40 \mathrm{~cm}$ em pontos da trilha de pisoteio e da floresta. $\mathrm{O}$ uso do solo não provocou alterações nos valores médios de densidade do solo $\left(1,25 \mathrm{~kg} \mathrm{dm}^{-3}\right.$ na trilha e $1,22 \mathrm{~kg} \mathrm{dm}^{-3}$ na floresta) e umidade do solo $\left(293,15 \mathrm{~g} \mathrm{~kg}^{-1}\right.$ na trilha e $301,5 \mathrm{~g} \mathrm{~kg}^{-1}$ na floresta), mas provocou alteração na resistência à penetração na camada de 0 $20 \mathrm{~cm}(8,15 \mathrm{MPa}$ na trilha e 3,85 MPa na floresta). Quanto ao, $\mathrm{pH}$, acidez potencial (H+Al), $\mathrm{MO}$, soma de bases (SB) e a saturação de bases (V) não houve diferenças significativas entre as amostras da trilha de pisoteio e floresta. Conclui-se que o pisoteio do gado promoveu alterações na resistência à penetração na camada mais superficial do solo.

Palavras-chave: compactação do solo, mata ciliar, propriedades do solo.

\section{Cattle trampling and penetration resistance of Oxisol in riparian forest}

\begin{abstract}
Animal trampling without adequate humidity is one of the factors that causes plastic and non-recoverable deformations of the soil. The present work evaluated the physical properties and mechanical resistance of soil to penetration on the Oxisol of a forest fragment in Tremembé (SP). Soil samples with preserved structure were collected in the $0-20 \mathrm{~cm}$ and $20-40 \mathrm{~cm}$ layers at trampled sites and forest sites. Soil use did not cause changes in mean values of soil density $\left(1.25 \mathrm{~kg} \mathrm{dm}^{-3}\right.$ on the trail and $1.22 \mathrm{~kg} \mathrm{dm}^{-3}$ in the forest) nor in soil moisture $\left(293.15 \mathrm{~g} \mathrm{~kg}^{-1} \mathrm{on}\right.$ the $301.5 \mathrm{~g} \mathrm{~kg}^{-1}$ trail in the forest), but caused a change in penetration resistance in the $0-20 \mathrm{~cm}$ layer (8.15 MPa on the trail and $3.85 \mathrm{MPa}$ in the forest). As for $\mathrm{pH}$, potential acidity $(\mathrm{H}+\mathrm{Al})$, $\mathrm{OM}$, base sum (SB) and base saturation $(\mathrm{V})$, there were no significant differences between the
\end{abstract}


trampled areas and the forest tracks. It was concluded that cattle trampling promoted resistance to penetration in the most superficial layer of the soil.

Keywords: soil compaction, soil properties, riparian forest.

\section{INTRODUÇÃO}

As florestas ripárias são formações vegetais encontradas ao longo das margens de rios e outros tipos de cursos aluviais, inseridas em regiões de solo fértil e úmido no fundo dos vales (Sanchez et al., 1999) exercendo funções fundamentais dentro do ecossistema, representando uma forte relação de interdependência entre os ambientes aquático e terrestre (Ferreira e Cortes, 1997). No entanto, estas formações estão entre os ecossistemas que apresentam o maior grau de degradação oriundo de ações antrópicas no Brasil (Vilela et al., 1998; Costa e Voltolini, 2013). Apesar da legislação brasileira resguardar a vegetação ribeirinha, muitas dessas áreas têm sofrido constantes influências antrópicas e alterações em sua estrutura original e composição, promovendo a remoção da vegetação nativa, devido a sua utilização para fins agrícolas, para a pecuária (Hosten e Whitridge, 2007), construção de casas (Carvalho et al., 2009) e intensa exploração de madeira (Jesus et al., 2007).

Atualmente, a região do Vale do Paraíba caracteriza-se como região de grande industrialização no eixo Rio - São Paulo, mas passou por inúmeros ciclos de atividade agrícola, sendo posteriormente substituída pela pecuária que perdura até os dias de hoje em alguns municípios, o que implicou na derrubada da maior parte da floresta nativa da região, incluindo as florestas ripárias. Aliado a esse processo de remoção da vegetação nativa e instalação de pastagens mal manejadas, observa-se, com frequência, trilhas de pisoteio de gado, em áreas ripárias, o que pode ser um dos condicionantes dos efeitos de degradação dos solos do Vale do Paraíba.

Entre os efeitos ocasionados pelo pisoteio do gado nos solos ripários, o mais comum é a compactação do solo, que resulta na diminuição da porosidade e da quantidade de água infiltrada, podendo aumentar as enxurradas e reduzir a disponibilidade hídrica às plantas (Kauffman e Krueger, 1984; Martin e Chambers, 2001; Griscom et al., 2005; Álvarez-Yépiz et al., 2008; Pereira Júnior et al., 2014).

Neste contexto, o objetivo deste estudo foi determinar e avaliar as possíveis modificações em algumas propriedades físico, químicas e a resistência a penetração de um Latossolo Vermelho Amarelo sob uma floresta ripária e sob trilha de pisoteio de gado, no município de Tremembé (SP), no Vale do Paraíba.

\section{MATERIAIS E MÉTODO}

O estudo foi conduzido em um Latossolo Vermelho Amarelo de um fragmento de floresta ripária localizado à margem direita do rio Paraíba do Sul, no bairro rural do Padre Eterno, no município de Tremembé (SP) sob as coordenadas 2256'21.70'’S e 45³2'29.09' 'O.

O clima característico da região é o Cwa-mesotérmico úmido, com verões quentes e invernos amenos e temperatura média anual de $21^{\circ} \mathrm{C}$, segundo a classificação de Köppen (Pinheiro et al., 2004). No fragmento de floresta, próximo à margem do rio Paraíba, existe uma trilha de passagem de bovinos, utilizada para este fim por, aproximadamente, 20 anos.

Para o delineamento de um espaço amostral, inteiramente casualizado, foram estabelecidos oito pontos aleatórios de amostragem de solo com a abertura de trincheiras, quatro destes, dispostos na trilha utilizada para passagem do gado e denominados de " $T$ ", margeando a porção esquerda do Rio Paraíba do Sul, e outros quatro pontos em área sem o pisoteio de animais 
denominados de "F", localizados a 15 metros de distância da trilha em relação ao interior da floresta, paralelamente (Figura 1).

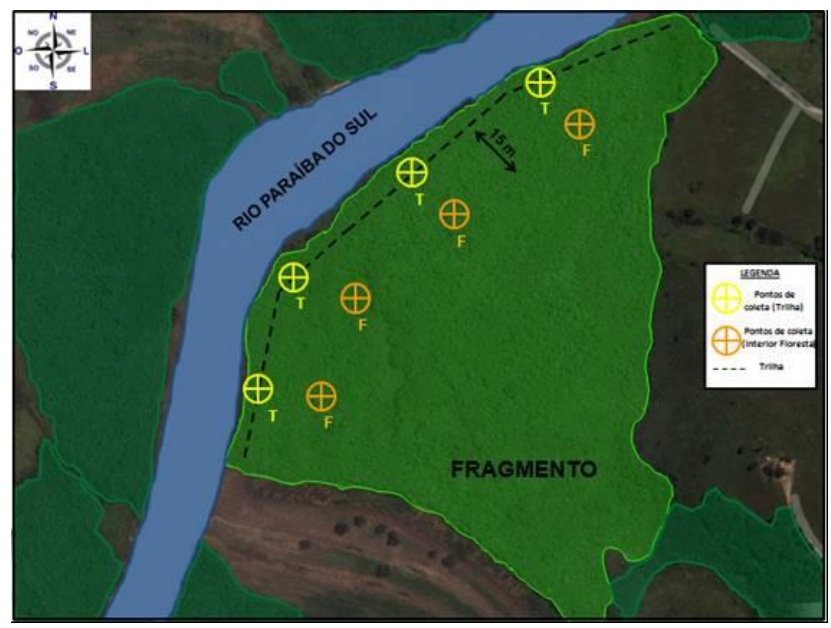

Figura 1. Disposição dos pontos de coleta no interior do fragmento florestal em Tremembé-SP. Os símbolos em amarelo indicam os pontos de coleta realizados na trilha " $T$ " e os em laranja os pontos de coleta realizados no interior da floresta " $F$ ". O caminho tracejado em preto indica a trilha mantida pelo pisoteio de bovinos e que dá acesso às propriedades circunvizinhas.

Fonte: adaptado de Rezende (2004).

Para cada ponto de coleta foram retiradas quatro amostras indeformadas de solo utilizando anéis volumétricos de $100 \mathrm{~cm}^{3}$ nas profundidades de $0-20 \mathrm{~cm}$ e de $20-40 \mathrm{~cm}$, conforme metodologia adaptada de Souza et al. (2003) e Oliveira Filho et al.(2004). O material coletado foi acondicionado em sacos plásticos e enviados ao Laboratório de Solos do Departamento de Ciências Agrárias da Universidade de Taubaté (SP).

No laboratório os anéis contendo as amostras de solo foram previamente identificados, pesados e dispostos em latas de metal numeradas, sendo posteriormente colocados em estufa à $110^{\circ} \mathrm{C}$ por $48 \mathrm{~h}$. Após este período as amostras foram pesadas a fim de se obter a densidade atual e umidade total (Embrapa, 1997).

Em seguida as amostras de solo foram retiradas dos anéis, destorroadas com rolo de madeira e peneiradas em trama de $2 \mathrm{~mm}$, sendo novamente acondicionadas em sacos plásticos para posteriores análises de $\mathrm{pH}$ em solução $\mathrm{CaCl}_{2}$, acidez potencial $(\mathrm{H}+\mathrm{Al})$ pelo método do $\mathrm{pH}$ SMP; matéria orgânica do solo (MO) por meio de oxidação em presença de ácido sulfúrico; soma de bases (SB) e a saturação por bases $(\mathrm{V})$, conforme metodologias descritas em Embrapa (1997).

Com a finalidade de avaliar a resistência à penetração (RP) dos solos da área do fragmento florestal foi utilizado um penetrômetro de impacto com a realização de oito coletas para cada ponto, sendo uma a cada $5 \mathrm{~cm}$ até a profundidade de $40 \mathrm{~cm}$, totalizando 64 aferições (Rezende, 2004; Araújo et al., 2007; Torres et al., 2012).

Os dados foram submetidos à análise de variância pelo teste $\mathrm{F}$ e quando significativos, foram aplicados o teste Tukey ao nível de 5\% de probabilidade.

\section{IPABH}




\section{RESULTADOS E DISCUSSÃO}

A densidade do solo não foi alterada pelo uso do solo, bem como pela profundidade (Tabela 1), visto que até os $20 \mathrm{~cm}$ a densidade média foi de $1,25 \mathrm{~kg} \mathrm{dm}^{-3} \mathrm{e} 1,22 \mathrm{~kg} \mathrm{dm}^{-3}$, na trilha e floresta respectivamente, e de $1,20 \mathrm{~kg} \mathrm{dm}^{-3}$ e $1,24 \mathrm{~kg} \mathrm{dm}^{-3}$ na camada de $20-40 \mathrm{~cm}$, para trilha e floresta respectivamente.

Tal fato pode estar relacionado diretamente com a baixa periodicidade do tráfego do gado pela área de estudo e pelo número de animais que transitam regularmente pela trilha.Valores semelhantes foram encontrados por Silva et al. (2000), que ao avaliarem as intensidades de pisoteio animal em área de integração lavoura-pecuária verificaram que o pisoteio animal teve pequeno efeito sobre as características físicas, o que foi atribuído à manutenção de resíduo vegetal na superfície do solo, de modo que o impacto da pata do animal não se dava diretamente sobre o solo.

Entretanto, Ortigara et al. (2014) encontraram altos valores de densidade do solo um Latossolo Vermelho distrófico em área de pastejo indicando que o pisoteio animal influenciou negativamente no estado de compactação do solo. Vzzotto et al. (2000) constataram que nos nos primeiros $5 \mathrm{~cm}$ de um Planossolo houve aumento da compactação da camada superficial do solo, quando submetido ao pisoteio animal.

Verificou-se que os valores de umidade inicial do solo não foram significativamente diferentes $(\mathrm{P}<0,05)$ na trilha e na floresta, bem como entre as camadas de $0-20 \mathrm{~cm}$ e $20-40 \mathrm{~cm}$ (Tabela 1). Todavia observa-se que na média houve tendência de menor umidade na camada superficial, e de maior umidade nos pontos coletados na floresta. Esse comportamento pode estar associado Verificou-se que os valores de umidade inicial do solo diminuíram, à medida que foi se colocando os animais nos referidos piquetes.

Esse comportamento está associado ao pisoteio e a redução do estrato herbáceo, devido ao consumo pelos animais, de modo que a retirada da cobertura vegetal contribuiu para a diminuição do sombreamento e pela ausência de serapilheira devido ao trânsito de animais que mantém o local sempre "limpo" enquanto que a presença da mesma na floresta evita a atuação mais intensa da radiação solar na camada superficial do solo, com consequente evaporação da água, bem comocom o lençol freático que em áreas próximas a cursos d'água tendem a ser mais rasos. $\mathrm{Na}$ área de floresta a umidade tende a ser maior nos primeiros $20 \mathrm{~cm}$, pelo fato da existência de cobertura vegetal e serapilheira, garantindo o sombreamento do solo, proteção térmica e retenção da umidade.

Situação semelhante foi encontrada por Schneider et al. (1978) para um Latossolo em que áreas sem pisoteio do gado a umidade obtida foi de $35,12 \%$ contra $34,54 \%$ em áreas onde o pisoteio era efetivo. Os autores chegaram à conclusão de que o pisoteio diminuiu a umidade do solo, porém com valores não significativos atribuindo essa pequena diferença as chuvas que caíram diariamente durante a execução do trabalho.

A intensidade do pisoteio animal na camada $0-20 \mathrm{~cm}$ da trilha aumentou o valor médio de resistência a penetração, quando comparado a floresta (Tabela 1, Figura 1). Os valores foram superiores a 2,5 MPa o que é considerado por Camargo e Alleoni (2006); Petean et al. (2010) valores limitantes ao crescimento radicular. Carvalho et al. (2012) encontraram valores de resistência mecânica média do solo de até $4 \mathrm{MPa}$; No entanto, em solos não revolvidos anualmente são toleráveis valores de resistência até $4 \mathrm{MPa}$, devido à permanência e continuidade de poros, atividade biológica mais ativa e maior estabilidade de agregados.

$\mathrm{Na}$ camada sub-superficial os valores foram menores comparados aos de superfície e não diferiram significativamente entre trilha $(1,52 \mathrm{MPa})$ e floresta $(0,85 \mathrm{MPa})$. Em uma área experimental de pastejo sob Latossolo Vermelho distrófico Torres et al. (2012) encontraram valores decrescentes de resistência à penetração. 
Tabela 1. Valores médios de densidade aparente do solo, umidade atual, resistência à penetração em solo sob trilha de pisoteio e solo sob floresta ripária.

\begin{tabular}{ccc}
\hline Camada & Trilha & Floresta \\
\hline $0-20 \mathrm{~cm}$ & $1,25 \pm 0,04 \mathrm{~ns}$ & $1,22 \pm 0,05 \mathrm{~ns}$ \\
$20-40 \mathrm{~cm}$ & $1,20 \pm 0,05 \mathrm{~ns}$ & $1,24 \pm 0,03 \mathrm{~ns}$ \\
& Uensidade Aparente $\left(\mathrm{kg} \mathrm{dm}^{-3}\right)$ \\
$0-20 \mathrm{~cm}$ & $240,9 \pm 5,04 \mathrm{~ns}$ & $356,1 \pm 10,14 \mathrm{~ns}$ \\
$20-40 \mathrm{~cm}$ & $345,4 \pm 13,39 \mathrm{~ns}$ & $346,9 \pm 8,04 \mathrm{~ns}$ \\
& Resistência à penetração $(\mathrm{MPa})$ \\
$0-20 \mathrm{~cm}$ & $8,15 \pm 0,55 \mathrm{~A}$ & $3,85 \pm 0,41 \mathrm{~B}$ \\
$20-40 \mathrm{~cm}$ & $1,52 \pm 0,33 \mathrm{~ns}$ & $0,85 \pm 0,07 \mathrm{~ns}$ \\
\hline
\end{tabular}

Média \pm desvio padrão. Letras diferentes indicam diferenças entre as médias $(\mathrm{p}<0,05)$. NS=médias não diferem.

A resistência à penetração do solo (RP) é uma medida indireta da compactação. A compactação do solo ocasionada pelo pisoteio pode estar relacionada a diversos fatores como a umidade elevada do solo durante o pastejo, o pastoreio contínuo a alta carga animal e a baixa quantidade de forragem nas áreas (Santi et al., 2004).

Neste estudo os valores de resistência a penetração (Figura 1) tendem a diminuirem no solo sob floresta. Segundo Vzzotto et al. (2000), em solos de várzea, a resistência do solo aumenta com os anos de intensivo pisoteio manifestando-se de maneira mais severa nas camadas mais superficiais.

Segundo Schneider et al. (1978) o maior impacto provocado pelo gado nas camadas superficiais do solo está diretamente relacionado com a concentração da pressão em área muito pequena, no caso do seu casco, ocasionando maior resistência mecânica do solo em locais específicos. Sampaio e Guarino (2007) obtiveram valores de resistência a penetração que variaram de $3 \mathrm{~kg} \cdot \mathrm{cm}^{-2}$ para areas com alta intensidade de pisoteio do gado a $0,7 \mathrm{~kg} . \mathrm{cm}^{-2} \mathrm{em}$ área sem a presença destes animais a mais de 13 anos sendo que este estudo as profundidades de aferição não foram informadas.

Os resultados referentes ao $\mathrm{pH}$ do solo indicaram níveis de acidez alto para todas as situações. Latossolos comumente variam entre ácidos a fortemente ácidos, com $\mathrm{pH}$ em torno de 4,5-5,0. Além disso, os solos brasileiros tendem a serem naturalmente mais ácidos, principalmente, aqueles que se encontram em locais degradados (Veloso et al., 1992).

Baixos valores de $\mathrm{pH}$ no solo podem resultar em problemas para a manutenção das áreas florestais uma vez que influencia a disponibilidade de nutrientes gerando condições inóspitas devido a maior disponibilidade de metais pesados (Costa e Zocche, 2009).

Araújo (2010) promovendo uma análise dos efeitos do pastoreio de bovinos em áreas de floresta ripária do Rio Grande do Sul obteve, à profundidade de 0 a $30 \mathrm{~cm}$, medidas de $\mathrm{pH}$ variando entre 4,9 a 6,3 para um fragmento ripário com a presença do gado e 5,1 a 6,5 para um fragmento onde os animais eram ausentes. A autora atribuiu as pequenas variações entre as áreas à proximidade entre elas, o que permitiu que esses fragmentos apresentassem condições edáficas e topográficas semelhantes. 


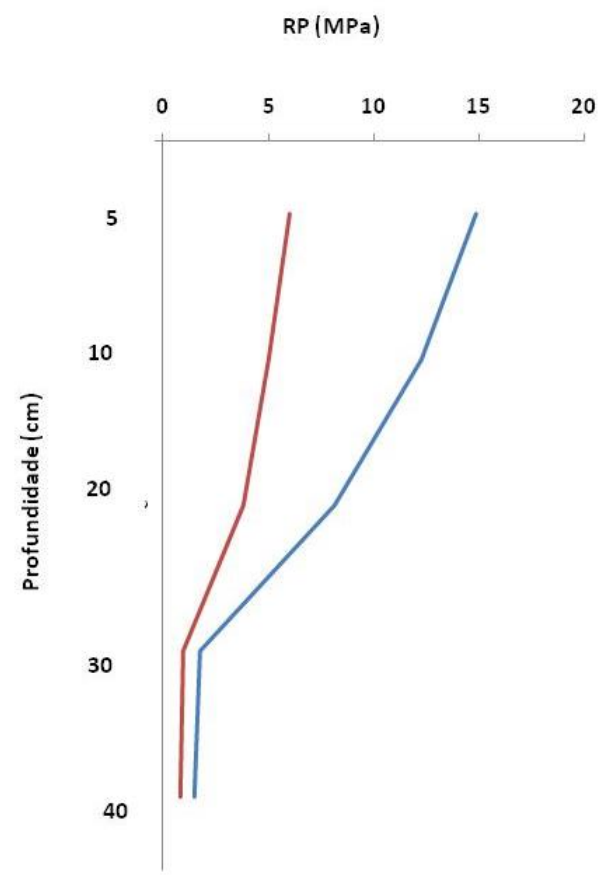

Figura 1. Resistência à penetração (RP) em Latossolo Vermelho Amarelo ao longo da profundidade, sob as situações de trilha (azul) e floresta (vermelho).

Para as variáveis químicas do solo $\left(\mathrm{pH} \mathrm{CaCl}_{2}\right.$, Matéria Orgânica, $\mathrm{H}+\mathrm{Al}$, Soma de Bases e Saturação por Bases) não ocorreram diferenças estatísticas entre a trilha e a florestas (Tabela 2).

Tabela 2. Valores médios de pH, Matéria Orgânica, H+Al, Soma de base e Saturação por Bases em trilha de pisoteio e solo sob floresta ripária.

\begin{tabular}{|c|c|c|}
\hline Camada & Trilha & Floresta \\
\hline & \multicolumn{2}{|c|}{$\mathrm{pH} \mathrm{CaCl}{ }_{2}$} \\
\hline $0-20 \mathrm{~cm}$ & $3,8 \pm 0,06 \mathrm{~ns}$ & $3,8 \pm 0,09 \mathrm{~ns}$ \\
\hline \multirow[t]{2}{*}{$20-40 \mathrm{~cm}$} & $3,8 \pm 0,07 \mathrm{~ns}$ & $3,8 \pm 0,13 \mathrm{~ns}$ \\
\hline & \multicolumn{2}{|c|}{ Matéria Orgânica $\left(\mathrm{g} \mathrm{dm}^{-3}\right)$} \\
\hline $0-20 \mathrm{~cm}$ & $9,0 \pm 1,29 \mathrm{~ns}$ & $8,0 \pm 2,27 \mathrm{~ns}$ \\
\hline \multirow[t]{2}{*}{$20-40 \mathrm{~cm}$} & $7,8 \pm 0,63 \mathrm{~ns}$ & $5,5 \pm 1,44 \mathrm{~ns}$ \\
\hline & \multicolumn{2}{|c|}{$\mathrm{H}+\mathrm{Al}\left(\mathrm{mmol}_{\mathrm{c}} \mathrm{dm}^{-3}\right)$} \\
\hline $0-20 \mathrm{~cm}$ & $\begin{array}{c}100,8 \pm 28,74 \\
n s\end{array}$ & $99,8 \pm 31,94 \mathrm{~ns}$ \\
\hline \multirow[t]{2}{*}{$20-40 \mathrm{~cm}$} & $93,0 \pm 20,81 \mathrm{~ns}$ & $91,3 \pm 29,52 \mathrm{~ns}$ \\
\hline & \multicolumn{2}{|c|}{ Soma de Bases $\left(\mathrm{mmol}_{\mathrm{c}} \mathrm{dm}^{-3}\right)$} \\
\hline $0-20 \mathrm{~cm}$ & $9,8 \pm 0,89 \mathrm{~ns}$ & $8,6 \pm 0,23 \mathrm{~ns}$ \\
\hline \multirow[t]{2}{*}{$20-40 \mathrm{~cm}$} & $8,5 \pm 0,53 \mathrm{~ns}$ & $7,8 \pm 0,00 \mathrm{~ns}$ \\
\hline & \multicolumn{2}{|c|}{ Saturação por Bases (\%) } \\
\hline $0-20 \mathrm{~cm}$ & $10,5 \pm 2,33 \mathrm{~ns}$ & $11,3 \pm 3,54 \mathrm{~ns}$ \\
\hline $20-40 \mathrm{~cm}$ & $9,5 \pm 1,94 \mathrm{~ns}$ & $12,8 \pm 6,12 \mathrm{~ns}$ \\
\hline
\end{tabular}

Média \pm desvio padrão. Letras diferentes indicam diferenças entre as médias $(\mathrm{p}<0,05)$. NS=médias não diferem. 
Quanto aos teores de matéria orgânica do solo, a camada mais superficial, tanto na trilha quanto na floresta, apresentaram valores discretamente mais elevados $\left(9,0 \mathrm{~g} \mathrm{dm}^{-3} \mathrm{e} 8,0 \mathrm{~g} \mathrm{dm}^{-3}\right.$, respectivamente), se comparados com as profundidades de $20-40 \mathrm{~cm}\left(7,8 \mathrm{~g} \mathrm{dm}^{-3}\right.$ para trilha; $5,5 \mathrm{~g} \mathrm{dm}^{-3}$ para floresta).

A acidez potencial $\left(\mathrm{H}^{+}+\mathrm{Al}\right)$, a soma de bases $(\mathrm{SB})$ e a saturação por bases $(\mathrm{V})$ também apresentaram o mesmo padrão de distribuição da MO sendo que os maiores valores, embora discretos, foram observados nas camadas superficiais $(0-20 \mathrm{~cm})$ quando comparados com as camadas mais profundas $(20-40 \mathrm{~cm}$ ) (Tabela 2). $\mathrm{O}$ valor de $\mathrm{V}$ para a área de trilha e floresta bem como para os dois níveis de profundidade foram classificados como muito baixos.

Portugal et al. (2010) avaliando as propriedades físico-químicas do solo em áreas com sistemas produtivos e floresta constituída na zona da mata mineira encontraram, sob Latossolo Vermelho Amarelo os maiores valores de acidez potencial na área de mata $\left(9,83 \mathrm{mmol}_{\mathrm{c}} \mathrm{dm}^{-3} \mathrm{a}\right.$ profundidade de 0 a $0,20 \mathrm{~m}$ e 8,45 $\mathrm{mmol}_{\mathrm{c}} \mathrm{dm}^{-3}$ de 0,20 a $0,40 \mathrm{~m}$ ) quando comparado a outros sistemas de uso como o laranjal, o canavial e o pasto. Os autores justificaram que o alto teor de acidez potencial pode estar relacionado com a quantidade de matéria orgânica presente no solo, por esta apresentar grupos funcionais responsáveis por liberar $\mathrm{H}$ que comporá os íons envolvidos na capacidade de troca catiônica do solo.

Os valores de SB e V\% foram menores na área de floresta às profundidades de 0,0 a 0,20 m $\left(0,47 \mathrm{mmol}_{\mathrm{c}} \mathrm{dm}^{-3}\right.$ e 4,6\%) e 0,20 a $0,40 \mathrm{~m}\left(0,21 \mathrm{mmol}_{\mathrm{c}} \mathrm{dm}^{-3}\right.$ e $\left.2,5 \%\right)$, para o estudo de Portugal et al. (2010). Os maiores teores de MO também foram encontrados na área de mata, para ambas as profundidades, variando entre 4,26 $\mathrm{mmol}_{\mathrm{c}} \mathrm{dm}^{-3}$ de 0,0 a $0,20 \mathrm{~m} \mathrm{e} \mathrm{3,08} \mathrm{mmol}_{\mathrm{c}}$ $\mathrm{dm}^{-3}$ de 0,20 a $0,40 \mathrm{~m}$. Caracterizando o solo sob diferentes usos e composição florística no Vale do Mucuri, MG Almeida (2009) encontrou baixos valores de soma de bases e saturação por bases para as áreas com cultura, pastagem e remanescente florestal de 4 municípios. $\mathrm{Na}$ área do $1^{\circ}$ município a soma de bases foi menor no remanescente florestal $\left(0,77 \mathrm{cmol}_{\mathrm{c}} \mathrm{dm}^{-3}\right)$ e a saturação por bases na cultura $(8,92 \%)$ enquanto que na área do $2^{\circ}$ município os valores de SB e V\% foram menores no remanescente $\left(1,17 \mathrm{cmol}_{\mathrm{c}} \mathrm{dm}^{-3}\right.$ e 9,50\%). Os município 3 e 4 apresentaram os menores valores de SB e V\% na área de cultura $\left(2,32 \mathrm{cmol}_{\mathrm{c} \mathrm{dm}} \mathrm{d}^{-3}\right.$ e $30,14 \%$; $0,44 \mathrm{cmol}_{\mathrm{c}} \mathrm{dm}^{-3}$ e $5,06 \%$, respectivamente). Os baixos teores de $\mathrm{SB}$ e V\% indicam uma baixa fertilidade do solo.

\section{CONCLUSÃO}

O solo sob a trilha de pisoteio mostrou maior degradação física comparada ao solo sob floresta evidenciada pelo aumento da resistência à penetração, apesar de manter a condição química semelhante à da floresta, com alta acidez e baixos valores de soma de bases e saturação por bases.

\section{REFERÊNCIAS}

\section{ALMEIDA, L. G. F. Caracterização do solo com diferentes usos e composição florística no} Vale do Mucuri - MG. 2009. 75 f. Dissertação (Mestrado em Produção Vegetal) Universidade Federal dos Vales do Jequitinhonha e Mucuri, Diamantina, 2009.

ÁLVAREZ-YÉPIZ, J. C.; MARTÍNEZ-YRÍZAR, A.; BÚRQUEZ A.; LINDQUIST, C. Variation in vegetation structure and soil properties related to land use history of oldgrowth and secondary tropical dry forests in northwestern Mexico. Forest Ecology and Management, v. 256, n. 3, p. 355-366, 2008. http://dx.doi.org/10.1016/ j.foreco.2008.04.049 
ARAÚJO, R.; GOEDERT, W. J.; LACERDA, M. P. C. Qualidade de um solo sob diferentes usos e sob Cerrado nativo. Revista Brasileira de Ciência do Solo, v. 31, p. 1099-1108, 2007. http://dx.doi.org/10.1590/S0100-06832007000500025

ARAÚJO, A. C. B. Efeito do pastoreio de bovinos sobre a estrutura de mata ciliar do Arroio do Espinilho em Sant'ana do Livramento, RS, Brasil. 2010. 93 f. Dissertação (Mestrado em Engenharia Florestal) - Universidade Federal de Santa Maria, Santa Maria, 2010 .

CAMARGO, O. A. de; ALLEONI, L. R. F. Conceitos gerais de compactação do solo. 2006. Disponível em: http://www.infobibos.com/Artigos/CompSolo/Comp1.htm. Acesso em: 2 dez. 2016.

CARVALHO, J. A. S.; FERREIRA, P. R. S.; CORTEZ, L. S. L.; BRANDÃO, R.; SANTOS, M. J. D.; LIMA, E. V. Ocupações irregulares e impactos ambientais as margens do rio Branco - Boa Vista - PR - Bairro Francisco Caetano Filho. In: SEMINÁRIO INTERNACIONAL DE CIÊNCIAS DO AMBIENTE E SUSTENTABILIDADE NA AMAZÔNIA, 1., 2009, Manaus, AM. Anais... Manaus: SDS, 2009. p.1-9.

CARVAlHO, A. P. V.; DIAS, H. C. T.; PAIVA, H. N.; TONELlO, K. C. Resistência mecânica do solo à penetração na Bacia Hidrográfica do Riacho Fundo, Felixlândia MG. Revista Árvore, v. 36, n. 6, p. 1091-1097, 2012. http://dx.doi.org/10.1590/S010067622012000600010

COSTA, S.; ZOCCHE, J. J. Fertilidade de solos construídos em áreas de mineração de carvão na região sul de Santa Catarina. Revista Árvore, v. 33, n. 4, p. 665-674, 2009. http://dx.doi.org/10.1590/S0100-67622009000400009

COSTA, L; VOLTOLINI, J. C. Impacto do pisoteio de gado sobre floresta ripária no Vale do Paraíba, Tremembé, SP. Revista Biociências, Taubaté, v. 19, n. 1, p.93-103. 2013.

EMPRESA BRASILEIRA DE PESQUISA AGROPECUÁRIA. Manual de métodos de análise de solo. Rio de Janeiro: Centro Nacional de Pesquisas de Solos, 1997. 212 p.

EMPRESA BRASILEIRA DE PESQUISA AGROPECUÁRIA. Restauração ecológica de matas ripárias: uma questão de sustentabilidade. Planaltina, DF: Centro Nacional de Pesquisa de solos, 2010. $75 \mathrm{p}$.

FERREIRA, M. T.; CORTES, R. M. Estrutura e importância da mata ripária em sistemas fluviais da Bacia do Tejo. In: SIMPÓSIO DE HIDRÁULICA E RECURSOS HÍDRICOS, 1997, Moçambique. Anais... Moçambique: SILUSBA, 1997. p.1-6.

GRISCOM, H. P.; ASHTON, P. M. S.; BERLYN, G. P. Seedling survival and growth of native tree species in pastures: Implications for dry tropical forest rehabilitation in central Panama. Forest Ecology and Management, v. 218, p. 306-318, 2005. http://dx.doi.org/10.1016/j.foreco.2005.08.026

HOSTEN, P. E.; H. WHITRIDGE. Vegetation changes associated with livestock exclusion from riparian areas on the dead indian plateau of southwest Oregon. Medford District: Department of the Interior, Bureau of Land Management, 2007. Disponivel em: http://soda.edu/bioregion.html. Acesso em: 18 fev. 2014.

JANICKE, J. Ecological effects caused by the grazing of cattle on public lands. The Honors Journal: University of Colorado, v. 13, p. 76-82, 2008. 
JESUS, E. F.; RIBEIRO, W.; SOUSA, O. P.; TORRES, J. L. R. Caracterização e recomposição da mata ciliar do córrego Lanhoso. Revista Brasileira de Agroecologia, v. 2, n. 3, p. 18$28,2007$.

KAUFFMAN J. B.; KRUEGER W. C. Livestock impacts on riparian ecosystems and streamside management implications. A review. Journal of Range Management, v. 37, n. 5, p. 430-438, 1984. https://journals.uair.arizona.edu/index.php/jrm/article/.../7370.

MARTIN, D. W.; CHAMBERS, C. J. Restoring degraded riparian meadows: Biomass and species responses. Journal of Range Management, v. 54, n. 3, p. 284-291, 2001.

OLIVEIRA FILHO, A. T.; CARVALHO, D. A.; FONTES, M. A. L.; VAN DEN BERG, E.; CURI, N.; CARVALHO, W. A. C. Variações estruturais do compartimento arbóreo de uma floresta semidecídua alto-montana na chapada das Perdizes, Carrancas, MG. Revista Brasileira de Botânica, v. 27, n. 2, p. 291-309, 2004.

ORTIGARA, C.; KOPPE, E.; LUZ, F. B.; BERTOLLO, A. M.; KAISER, D. R.; SILVA, V. R. Uso do solo e propriedades físico-mecânicas de Latossolo Vermelho. Revista Brasileira de Ciência do Solo, v. 38, n. 2, p. 619-626, 2014 . http://dx.doi.org/10.1590/S010006832014000200026

PEREIRA JUNIOR, E. B.; SOUTO, J. S.; SOUTO, P. C.; HAFLE, O. M. Impactos do pisoteio ovino nos atributos físicos do solo em área de coqueiro-anão irrigado, na região do semiárido paraibano. Global Science And Technology, v. 7, n. 1, 2014.

PETEAN, L. P.; TORMENA, C. A.; ALVES, S. J. Intervalo hídrico ótimo de um latossolo vermelho distroférrico sob plantio direto em sistema de integração lavoura-pecuária. Revista Brasileira de Ciência do Solo, v. 34, n. 5, p. 1515-1526, 2010. http://dx.doi.org/10.1590/S0100-06832010000500004.

PINHEIRO, R. A.; FISCH, S. T. V.; ALMEIDA, A. A cobertura vegetal e as características do solo em área de extração de areia. Revista Biociências, v. 10, n. 3, p. 103-110, 2004.

PORTUGAL, A. F.; COSTA, O. D. V.; COSTA, L. M. Propriedades físicas e químicas do solo em áreas com sistemas produtivos e mata na região da Zona da Mata Mineira. Revista Brasileira de Ciência do Solo, v. 34, p. 575-585, 2010. http://dx.doi.org/10.1590/S010006832010000200032

REZENDE, M. V. O. Avaliação das propriedades físicas de um solo no controle de sua qualidade ambiental sob diferentes tipos de usos. 2004. 53f. Dissertação (Mestrado em Ciências Ambientais) - Universidade de Taubaté, Taubaté, 2004.

SAITO, M. A. Manejo de pastagens - Recursos naturais: Caracterização e conservação. São José dos Campos: Divisão Regional Agrícola, 1995. 143 p.

SAMPAIO, M. B.; GUARINO, E. S. G. Efeitos do pastoreio de bovinos na estrutura populacional de plantas em fragmentos de floresta ombrófila mista. Sociedade de Investigações Florestais (SIF), v. 31, n. 6, p. 1035-1046, 2007. http://dx.doi.org/10.1590/S0100-67622007000600008

SANCHEZ, M.; PEDRONI, F.; LEITÃO-FILHO, H. F.; CESAR, O. Composição florística de um trecho de floresta ripária na Mata Atlântica em Picinguaba, Ubatuba, SP. Revista Brasileira de Botânica, v. 22, n. 1, p. 1-26, 1999. http://dx.doi.org/10.1590/S010084041999000100006 
SANTI, G. R.; COLLARES, G. L.; REINERT, D. J.; REICHERT, J. M.; PELLEGRINI, A.; KUNZ, M.; KAISER, D. R. Efeito do pisoteio bovino na compactação de solo argiloso na região do planalto gaúcho. In: REUNIÃO BRASILEIRA DE MANEJO E CONSERVAÇÃO DO SOLO E ÁGUA, 15., 2004, Santa Maria, RS. Anais... Santa Maria: UFSM, 2004. p. 1-4.

SCHNEIDER, P. R.; GALVÃO, F.; LONGHI, S. J. Influência do pisoteio de bovinos em áreas $\begin{array}{llllllll}\text { florestais. Revista Floresta, v. 19, n. 1, p. 19-23, } 1978 . & \text { n. }\end{array}$ http://dx.doi.org/10.5380/rf.v9i1.6209

SILVA, V. R.; REICHERT, M. J.; REINERT, J. D. Densidade do solo, atributos químicos e sistema radicular do milho afetado pelo pastejo e manejo do solo. Revista Brasileira de Ciência do Solo, v. 24, n. 1,p. 191-199, 2000. http://dx.doi.org/10.1590/S010006832000000100021

SOUZA, J.S.; ESPÍRITO-SANTO, F. D. B.; FONTES, M. A. L.; OLIVEIRA-FILHO, A. T.; BOTEZELLI, L. Análise das variações florísticas e estruturais da comunidade arbórea de um fragmento de floresta semidecídua às margens do rio Capivari, Lavras-MG. Revista Árvore, v. 27, n. 2, p. 185-206, 2003. http://dx.doi.org/10.1590/S010067622003000200009

TORRES, J. L. R.; RODRIGUES JUNIOR, D. J.; SENE, G. A.; JAIME, D. G.; VIEIRA, D. M. S. Resistência à penetração em área de pastagem de capim Tifton, influenciada pelo pisoteio e irrigação. Bioscience Journal, v. 28, n. 1, p. 232-239, 2012.

VELOSO, C. A. C.; BORGES, A. L.; MUNIZ, A. S.; VEIGAS, I. A. Efeito de Diferentes Materiais no pH do Solo. Scientia Agricola, v. 49, n. 1, p. 123-128, 1992. http://dx.doi.org/10.1590/S0103-90161992000400016

VILELA, E.A.; OLIVEIRA FILHO, A.T.; CARVALHO, D.A.; CURI, N. Estudos florísticos e fitossociológicos em remanescentes de florestas ripárias do Baixo Paranaíba e Alto Rio São Francisco. Belo Horizonte: Companhia Energética de Minas Gerais, 1998.

VZZOTTO, V. R.; MARCHEZAN, E.; SEGABINAZZI, T. Efeito do pisoteio bovino em algumas propriedades físicas do solo de várzea. Revista Ciência Rural, v. 30, n. 6, p. 965-969, 2000. http://dx.doi.org/10.1590/S0103-84782000000600007 